\title{
FATIGUE FLEXURAL PERFORMANCE OF SHORT-SPAN REINFORCED \\ CONCRETE T-BEAMS CONSIDERING OVERLOADING EFFECT
}

\author{
CHENXU ZHUANG ${ }^{1}$, JINQUAN ZHANG ${ }^{2 *}$, RUINIAN JIANG ${ }^{3}$ \\ ${ }^{1,3}$ Department of Civil Engineering, New Mexico State University, \\ Las Cruces, New Mexico, USA \\ ${ }^{2}$ Research Institute of Highway, Ministry of Transport, Beijing, P.R. China
}

Received 26 October 2019; accepted 11 March 2020

\begin{abstract}
Traffic volume increase and higher proportion of heavier trucks have raised the potential risk of fatigue failure of short-span reinforced concrete beams. To investigate the fatigue behavior of short-span reinforced concrete beams with and without the overload effect, nine $5 \mathrm{~m}$ reinforced concrete T-beams were cast and tested. Two beams were tested under static loading to determine the ultimate strength; the remaining seven beams were subjected to cyclic loading with constant-amplitude load ranges. In addition, two of the seven beams were subjected to instant overloading. It was observed that the typical failure mode under cyclic loading was the fatigue fracture of tensile reinforcing bars. The introduction of instant overloading resulted in a remarkable reduction of fatigue life. Among all the parameters, the stress range of the reinforcing bars showed the highest effect on the fatigue life. In the end, the fatigue safety
\end{abstract}

\footnotetext{
* Corresponding author. E-mail: rioh_jqzhang@163.com
}

Chenxu ZHUANG (ORCID 0000-0002-8295-6940)

Jinquan ZHANG (ORCID 0000-0003-4363-7020)

Ruinian JIANG (ORCID 0000-0002-4485-1363) 
provisions in the current reinforced concrete beam design codes were evaluated based on the fatigue limits and $S$ - $N$ curves.

Keywords: fatigue life, fatigue limit, overloading, reinforced concrete beams, short-span, $S$ - $N$ curve, stress range.

\section{Introduction}

Reinforced concrete (RC) beam bridges have been widely used. According to the US National Bridge Inventory and Chinese official statistical reports, nearly $70 \%$ and $90 \%$ bridges were classified as concrete bridges in the United States and China, respectively. Fatigue failure of reinforced concrete beams was not a concern in the early days due to the low stress ranges (124 $\mathrm{MPa}$ to $140 \mathrm{MPa}$ ) in bridge members (Corley, Hanson, \& Helgason, 1978). However, in the last few decades, it has become an important issue as a result of the increasing traffic volumes and heaver trucks. The effect is much more severe in short and medium span bridges (Pimentel, Brühwiler, \& Figueiras, 2008; Yuan, Yan, Zhong, \& Liu, 2017).

The allowable truck weight limit has experienced a progressive increase. The general limit in the United States has exceeded $45 \mathrm{t}$ and the maximum limit even reached $74.4 \mathrm{t}$, as compared to the initial weight limit (33.2 t) stipulated by the Federal Government in 1956 (Al-Qadi, Wang, Ouyang, Grimmelsman, \& Purdy, 2016). Moreover, overloading happens more frequently. Heavy trucks between $80 \mathrm{t}$ and $130 \mathrm{t}$ were found on one bridge in China, which exceeded the double legal weight limit of $55 \mathrm{t}$ (Han, Wu, Cai, \& Chen, 2014). At the same time, a number of researchers (Gatti, 2019; Treacy \& Brühwiler, 2013) applied the Structural Health Monitoring (SHM) technique in collecting critical parameters in operating bridges, such as overloading, concrete strain, reinforcing bar strain, displacement, etc., which directly demonstrated the structural deterioration of bridge under real service conditions. As a result, the potential fatigue failure of RC beam bridges, especially for short and medium span reinforced concrete bridges, needs to be carefully investigated.

The first in-situ fatigue testing of RC beam bridges was reported in the AASHO Road Test (Highway Research Board, 1962). Two full-scale reinforced concrete beam bridges were subjected to real truck load for two and a half years. The test vehicles exerted a minimum stress of $113 \mathrm{MPa}$ and a stress range of $156 \mathrm{MPa}$ in the outermost reinforcing bars, which was much higher than that under normal service conditions. Fatigue failure occurred in the reinforcing bars and the final endurances were approximately 730000 cycles in one of the test bridges. This 
valuable discovery enhanced the awareness of the risk of fatigue failure of reinforced concrete beams.

More experimental investigations of fatigue behavior of RC beams were conducted later on with low stress ranges to simulate real service conditions. Under such low stress ranges, the fatigue fracture of tensile reinforcing bars was the typical failure mode (Helagson \& Hanson, 1974; Menzies, 1971; Roper \& Hetherington, 1982). The comprehensive results from the United States, Europe, Canada, and Japan were incorporated in the report of ACI 215R-74 (1997), including the influences of bar type, bar diameter, bending, etc. The most significant contribution was the fatigue limit equation, which was further adopted in the AASHTO LRFD Bridge Design Specifications (2012).

$$
f_{f}=165-0.33 f_{\min }
$$

where $f_{f}$ is the allowable stress range, $\mathrm{MPa} ; f_{\min }$ is the minimum stress (negative for compression), MPa.

In typical fatigue testing, load ranges adopted in most experiments were the fractions of the beam ultimate capacity, which did not reflect actual service conditions. Therefore, some researchers started to test large- and full-scale beams with typical live-to-dead load ratios (0.2 to 0.4) (Heffernan \& Erki, 2004). Bishara (1982) assessed the possibility of fatigue failure of RC beams by applying equivalent normal service loads on testing beams. No fatigue failure was observed and only increase of crack width and stress range was detected during the fatigue testing. Large-scale beams reinforced with multiple tensile reinforcing bars were tested by Matsumoto, Yumazumi, and Miyamoto (1990) and Johansson (2004). The fatigue life of RC beams was generally shorter than that of single reinforcing bar tested in air, since the fatigue fracture took place in the weakest reinforcing bar. The post-fatigue load capacity of beams was evaluated by Zhang, Peng, and Cai (2010). Two heavy trucks were applied on a RC beam after 43 years' service. The beam had severely deteriorated with concrete cracking, reinforcing bar corrosion, and concrete spalling. It was found that the load capacity of the beam was still larger than the expected. In recent years, the fatigue performance of RC beams with highstrength $\left(f_{y}>550 \mathrm{MPa}\right)$ reinforcing bars was evaluated by Soltani, Harries, Shahrooz, Russell, and Miller (2011). Based on two large-scale fatigue tests and the $S$ - $N$ curve established from 120 small-scale reinforced concrete beams, the current fatigue provision in the AASHTO LRFD Bridge Design Specifications (2012) was proven to be applicable to high-strength $\left(f_{y}<690 \mathrm{MPa}\right)$ reinforcing bars as well.

In order to improve the design of RC slab to meet the requirement of high-speed railway system, five full-scale fatigue tests were conducted 
by Tarifa, Zhang, Ruiz, and Poveda (2015). Based on the analysis of displacement history, a novel parameter (secondary displacement rate) was developed and proved to be strongly correlated with the fatigue life. Taking into consideration extremely low temperature in Canada, the effect of low temperature on the fatigue lives of RC beams was investigated by Mirzazadeh, Noël, and Green (2017). The beams under a low temperature exhibited a longer fatigue live than those under normal temperatures. The fatigue life of the beams increased $23 \%$ without shear reinforcement, and $67 \%$ with shear reinforcement. Besides, the shear resistance of RC beam bridge under normal service conditions is another concern. To this end, Teworte, Herbrand, and Hegger (2015) modified the static and fatigue shear assessment approach and concluded that the shear capacity of the aged RC beam bridges in Germany was 18\% higher than that based on the current design standards.

Recent studies reveal that overloading brings about a high potential risk of fatigue failure for bridge components (Biezma \& Schanack, 2007; Wardhana \& Hadipriono, 2003). Overloading leads to a remarkable reduction of fatigue life due to a significant increase of stress range in the tensile reinforcing bars. Three full-scale RC plate girders were tested under three load ranges, representing a standard design truck, $25 \%$ overloading, and $60 \%$ overloading. Only the beam under the standard design truck can sustain repetitive load for more than 2 million cycles (Zhang, Li, Mao, \& Dong, 2019). In addition, an instant overloading, represented by a passage of an overloaded truck, is a much more realistic condition during service life. Nagesh and Rao (2016) introduced an overloading of $54 \%$ higher than the maximum load on RC beams at the beginning and during the process of fatigue loading. The fatigue life of the beams reduced by $67 \%$ and $48 \%$ with the introduction of different time of overloading. The typical Miner's rule failed to explain this new finding.

Except for the experimental investigation of fatigue performance of $\mathrm{RC}$ beams, detailed fatigue assessment methods for RC bridges under real service conditions, including cumulative damage method and $\lambda$-coefficient method, were developed in the Eurocode. To improve the fatigue assessment accuracy, a number of parameters were taken into consideration, including the increased axle forces, improved precision in the stress range calculation, bridge span, bridge type, and reinforcement ratio (Herwig, 2008, Maddah, 2013; Olsson \& Pettersson, 2010; Pimentel et al., 2008).

Although the fatigue performance of RC beams has been investigated over the years, some new problems occur because of increased traffic volume and overloading. This research addresses the following concerns by testing large-scale RC T-beams with five constant stress ranges and two levels of instant overloading. First, fatigue testing of short-span RC 
T-beams with high fatigue relevance. Second, the applied load ranges Performance of Short-Span were corresponding to real service conditions and overloading as well. Third, the effect of overloading (simulating the passage of a heavy truck) on the fatigue performance of RC beams has become urgent, but little the preliminary study on this issue.

\section{Experimental program}

According to the standard drawings of short-span RC beams provided in JT/GQS 025-1984 (Transport Planning and Research Institute, 1984), the stress analysis results of reinforcing bars for bridges with spans of $10 \mathrm{~m}, 13 \mathrm{~m}, 16 \mathrm{~m}$, and $20 \mathrm{~m}$ were summarized in Table 1 . The dead load effect includes the beam self-weight (DL-1) and any other permanent objects on the bridge (DL-2). The design live load in the JTG D60-2015 (The Standardization Administration of the People's Republic of China, 2015) is Highway Grade I, corresponding to a 55 t truck. It consists of five axles, one front ( $3 \mathrm{t}$ ), two middle (12 t), and two rear (14 t) axles at spacings of $3 \mathrm{~m}, 1.4 \mathrm{~m}, 7 \mathrm{~m}$, and $1.4 \mathrm{~m}$, respectively. It is found from Table 1 that the beam with the smallest span $(10 \mathrm{~m})$ suffers the maximum stress in the outmost tensile reinforcing bars: $31.8 \mathrm{MPa}$ (DL-1), $31 \mathrm{MPa}$ (DL-2), and 123.1 MPa (LL).

Therefore, the fatigue performance of RC T-beam with a span of $10 \mathrm{~m}$ was evaluated with nine $1 / 2$ scale RC T-beams. The beams were cast at the same time using the same materials, and moist cured for 28 days.

Table 1. Design details of conventional simply supported reinforced concrete T-beams

\begin{tabular}{|c|c|c|c|c|c|c|c|}
\hline \multirow{2}{*}{$\begin{array}{l}\text { Span, } \\
\text { m }\end{array}$} & \multirow{2}{*}{$\begin{array}{c}\text { Tensile } \\
\text { Reinforcing } \\
\text { bars layout }\end{array}$} & \multicolumn{3}{|c|}{$\begin{array}{l}\text { Moment } \\
\text { at midspan }\end{array}$} & \multicolumn{3}{|c|}{$\begin{array}{l}\text { Maximum stress } \\
\text { in reinforcing bars }\end{array}$} \\
\hline & & $\begin{array}{l}\text { DL-1', } \\
\mathrm{kN} \cdot \mathrm{m}\end{array}$ & $\begin{array}{l}\mathrm{DL}-2^{2} \\
\mathrm{kN} \cdot \mathrm{m}\end{array}$ & $\begin{array}{c}\mathrm{LL}^{3}, \\
\mathrm{kN} \cdot \mathrm{m}\end{array}$ & $\begin{array}{l}\text { DL-1, } \\
\text { MPa }\end{array}$ & $\begin{array}{l}\text { DL-2, } \\
\text { MPa }\end{array}$ & $\begin{array}{l}\text { LL, } \\
\mathrm{MPa}\end{array}$ \\
\hline 10 & $2-(2 \Phi 32+2 \Phi 28)$ & 125.5 & 122.4 & 485.7 & 31.8 & 31.0 & 123.1 \\
\hline 13 & $2-(3 \Phi 32+2 \Phi 28)$ & 273.7 & 211.9 & 670.2 & 44.3 & 34.3 & 108.4 \\
\hline 16 & $2-(5 \Phi 32)$ & 344.3 & 325.8 & 890.9 & 41.4 & 39.2 & 107.2 \\
\hline 20 & $2-(7 \Phi 32)$ & 375.2 & 515.7 & 1287.8 & 29.0 & 39.9 & 99.6 \\
\hline
\end{tabular}

Note:

1 DL-1 denotes the load effect due to beam self-weight;

2 DL-2 denotes the load effect due to any other permanent objects affixed to the beam;

${ }^{3}$ LL denotes the design live load effect. 
All beams were of the same size with a T cross-section and a length of $5 \mathrm{~m}$. Four $12 \mathrm{~mm}$ hot rolled ribbed bars (HRB400) were used as the main longitudinal tensile bars. In addition, the other type of $8 \mathrm{~mm}$ round bars (R235) were utilized in compression and for stirrups at a spacing of 200 $\mathrm{mm}$. Six uniaxial tensile tests were conducted on each type of reinforcing bars in line with codes of GB/T 1499.2-2018 (National Standard of the People's Republic of China, 2018) and GB/T 1499.1-2017 (National Standard of the People's Republic of China, 2017), respectively. The mean yield and ultimate strength of HRB400 were $441.8 \mathrm{MPa}$ and $606.3 \mathrm{MPa}$. Similarly, the mean yield and ultimate strength of R235 were $335.1 \mathrm{MPa}$ and $526.8 \mathrm{MPa}$. In addition, the concrete compressive strength was determined with a mean value of $50.1 \mathrm{MPa}$ using nine standard cubic specimens $(100 \mathrm{~mm} \times 100 \mathrm{~mm} \times 100 \mathrm{~mm})$ at the time of the fatigue testing. A consistent concrete cover of $30 \mathrm{~mm}$ was designed for the whole section. The details of the RC beam are shown in Figure 1.

The beams were divided into three groups.

1. Two beams for static tests, designated with $S$ (S-1 and S-2).

2. Five beams for fatigue tests under constant-amplitude load ranges (F-1 to F-5). The beams were subjected to five load ranges in an ascending order. To simulate real service conditions, a minimum load was set at $5 \mathrm{kN}$ and a stress of $31 \mathrm{MPa}$ in the outmost tensile reinforcing bars was measured, equivalent to the DL-2 effect. The DL-1 effect was not taken into consideration since the data were

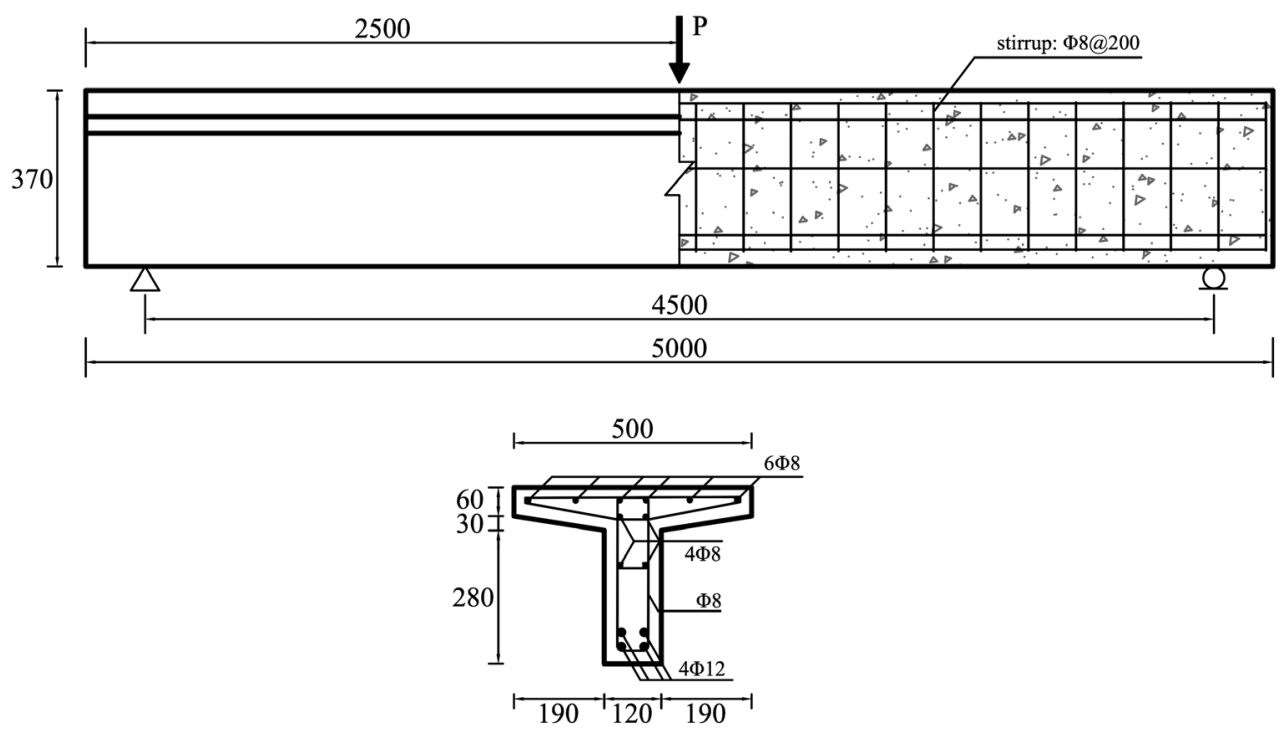

Figure 1. Details of the RC beams (unit: $\mathrm{mm}$ ) 
recorded after test setup. The maximum loads increased from $17.5 \mathrm{kN}$ to $35 \mathrm{kN}$. First, the maximum load on beam F-1 was set at $17.5 \mathrm{kN}$ to reproduce the standard design live load (123.1 MPa). For beam F-2, the maximum load was increased to $21 \mathrm{kN}$ (20\% overloading) to exert a stress range (163 MPa) that was approximately the fatigue limit prescribed in the GB 50010-2015 (Standardization Administration of the People's Republic of China, 2015), corresponding to a minimum fatigue life of 2 million cycles. The remaining three beams (F-3, F-4 and F-5) were subjected to maximum loads with a progressive increase of $3.5 \mathrm{kN}$ or $7 \mathrm{kN}$, representing overload levels of $40 \%, 60 \%$ and $100 \%$.

3. Two beams for fatigue tests with instant overloading (F-6 and F-7). Pre-set load ranges on beams F-6 (5-17.5 kN) and F-7 (5-21 kN) were consistent with those on beams F-1 and F-2, respectively. Two levels ( $7 \mathrm{kN}$ and $3.5 \mathrm{kN}$ ) of instant overloading were introduced on these two beams for just one cycle after 2 million cycles, corresponding to $20 \%$ and $40 \%$ overloading as compared with the standard design live load. The details of the tests are summarized in Table 2 .
Performance

of Short-Span

Reinforced

Concrete T-Beams

Considering

Overloading Effect

Table 2. Static and fatigue loading test details and results

\begin{tabular}{|c|c|c|c|c|c|c|}
\hline Test groups & Beam & $\begin{array}{l}\text { Load } \\
\text { Range, } \\
\text { kN }\end{array}$ & $\begin{array}{l}\text { Maximum } \\
\text { Load, } \\
\text { kN }\end{array}$ & $\begin{array}{c}\text { Average } \\
\text { Stress Range, } \\
\text { MPa }\end{array}$ & $\begin{array}{l}\text { Number } \\
\text { of Cycles to } \\
\text { Failure }\end{array}$ & $\begin{array}{l}\text { Failure } \\
\text { Mode }\end{array}$ \\
\hline \multirow{2}{*}{ Static } & S-1 & - & $P U=67$ & - & - & Yielding \\
\hline & $\mathrm{S}-2$ & - & $P u=63$ & - & - & Yielding \\
\hline \multirow{5}{*}{$\begin{array}{c}\text { Fatigue } \\
\text { (constant } \\
\text { amplitude) }\end{array}$} & $\mathrm{F}-1$ & $5-17.5$ & $0.27 P u$ & 126 & $>9000000$ & No failure \\
\hline & $\mathrm{F}-2$ & $5-21$ & $0.32 P u$ & 163 & 3764000 & Fatigue \\
\hline & $\mathrm{F}-3$ & $5-24.5$ & $0.38 P u$ & 181 & 1123000 & Fatigue \\
\hline & $\mathrm{F}-4$ & $5-28$ & $0.43 P u$ & 220 & 555000 & Fatigue \\
\hline & $\mathrm{F}-5$ & $5-35$ & $0.54 P u$ & 300 & 384000 & Fatigue \\
\hline \multirow{4}{*}{$\begin{array}{c}\text { Fatigue } \\
\text { (with } \\
\text { instant } \\
\text { overloading) }\end{array}$} & \multirow{2}{*}{ F-6 } & $5-17.5$ & \multirow{2}{*}{$0.27 P u$} & $121(<2 \text { O०० O०০) })^{1}$ & \multirow{2}{*}{3401000} & \multirow{2}{*}{ Fatigue } \\
\hline & & $(7)^{3}$ & & $185(\geq 2000000)^{2}$ & & \\
\hline & \multirow{2}{*}{$\mathrm{F}-7$} & $5-21$ & \multirow{2}{*}{$0.32 P u$} & $165(<2000000)^{1}$ & \multirow{2}{*}{2697000} & \multirow{2}{*}{ Fatigue } \\
\hline & & $(3.5)^{3}$ & & $201(\geq 2000000)^{2}$ & & \\
\hline
\end{tabular}

Note:

1 average stress range before overloading;

2 average stress range after overloading;

${ }^{3}$ the instant overloading of $7 \mathrm{kN}$ and $3.5 \mathrm{kN}$ were introduced on beams $\mathrm{F}-6$ and F-7, respectively. 


\section{Test setup and instrumentation}

The tests were conducted using a $100 \mathrm{kN}$ hydraulic actuator with displacement control for static testing and load control for fatigue testing, respectively. The loading frequency applied was retained at $3 \mathrm{~Hz}$ to avoid overheating (Mallet, 1991) and hysteresis effect (Papakonstantinou, Petrou, \& Harries, 2001) in the reinforcing bars. In the static testing, a progressively increasing displacement was exerted until the beams failed. To evaluate the fatigue performance of the beams after a certain number of cycles, a stepwise static testing up to the upper fatigue load (the upper limit of load range in Table 2) was continued. Note that the readings of strains (concrete and reinforcing bars) and deflections were set to zero after designated cycles, thus, only the variation under quasi-static testing was recorded, the residual strains and deflections were not considered in this paper.

Each beam was simply supported by two laminated rubber bearings and subjected to a point load at the midspan. Six internal strain gages were installed on the two outmost tensile reinforcing bars at three locations. Thirteen external concrete strain gages were placed at sections $\mathrm{A}-\mathrm{A}, \mathrm{B}-\mathrm{B}, \mathrm{C}-\mathrm{C}$ and $\mathrm{D}-\mathrm{D}$ (see Figure 2), respectively. In addition, the displacements at five locations were measured with linear variable displacement transducers (LVDTs). The strain and displacement histories were recorded using a data acquisition system (UCAM-60B) manufactured by KYOWA. Meanwhile, the crack evolution (crack length, location) was recorded by visual inspection. The crack width was measured via an automate crack width detector (ZBL-F-103) with a resolution of $0.01 \mathrm{~mm}$. The instrumentation layout is shown in Figure 2 and a photo of the test site is shown in Figure 3.

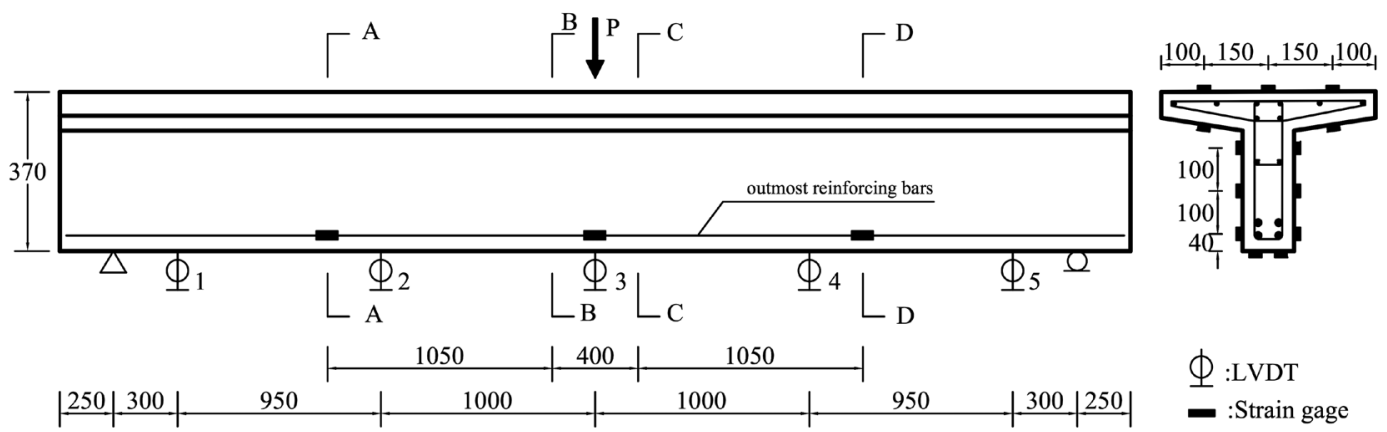

Figure 2. Test setup and instrumentation (unit: $\mathrm{mm}$ ) 


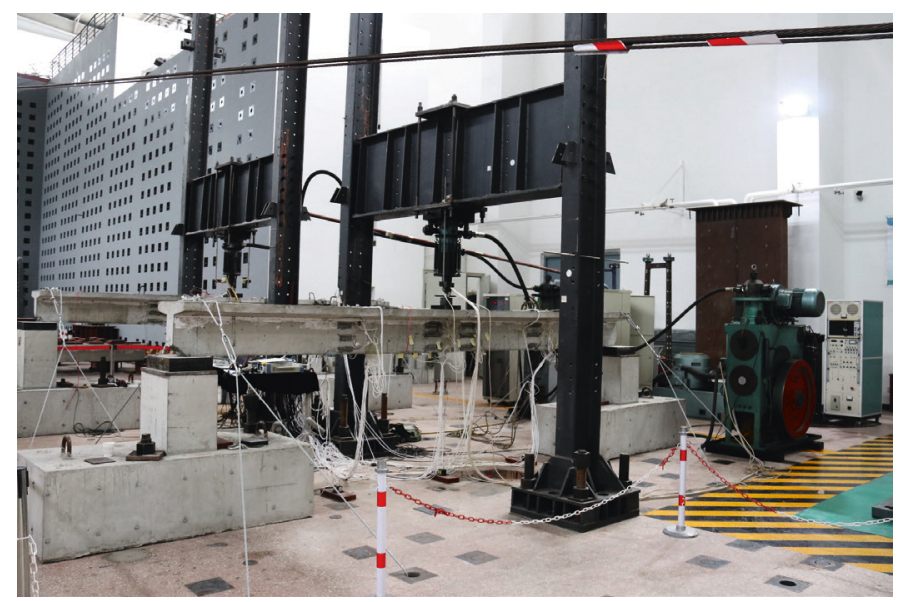

Fatigue Flexural

Performance

of Short-Span

Reinforced

Concrete T-Beams

Considering

Overloading Effect

Figure 3. Test layout in the lab

\section{Static test results}

Two beams (S-1 and S-2) were tested under static loading. The test results of these two beams were very similar and the averaged values was reported hereafter. The ultimate load was determined as $65 \mathrm{kN}$ (see Table 2). After static testing, the concrete cover was removed at the midspan to check the condition of the internal reinforcing bars. No fracture was observed in any tensile reinforcing bars in beams S-1 and S-2. The primary failure mode was concrete crush in compression preceding the ductile fracture of reinforcing bars in tension, as shown in Figure 4a.

\section{Fatigue test results}

Seven beams (F-1 to F-7) were tested under fatigue loading. The details of load ranges, stress ranges in the outmost reinforcing bars, number of cycles to failure, and failure modes are summarized in Table 2. Only Beam F-1 did not fail even after 9 million cycles and was assumed to possess an infinite fatigue life. The other six beams under fatigue testing failed at different loading cycles.

The primary failure mode under fatigue testing was the fatigue fracture of tensile reinforcing bars, which was consistent with previous experimental results (Schlalli \& Briihwiler, 1998; Herwig, 2008; Pimentel et al., 2008). Several cracks (one to three) developed remarkably near the midspan followed by the fatigue fracture of one or two outmost reinforcement bars. The surfaces at the fracture section 


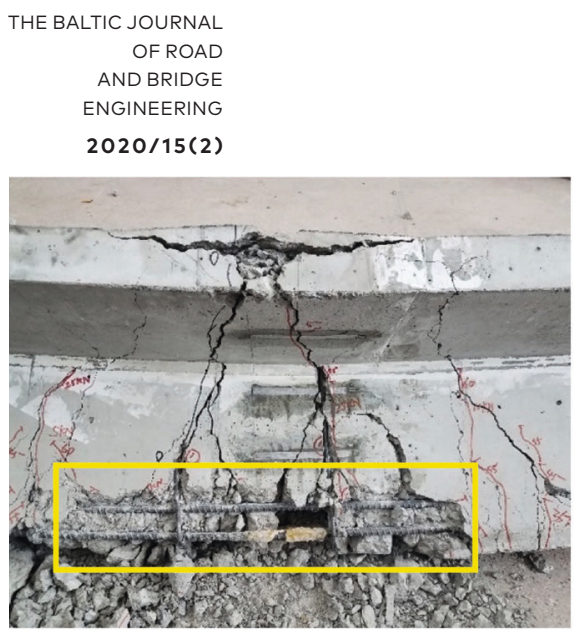

a)
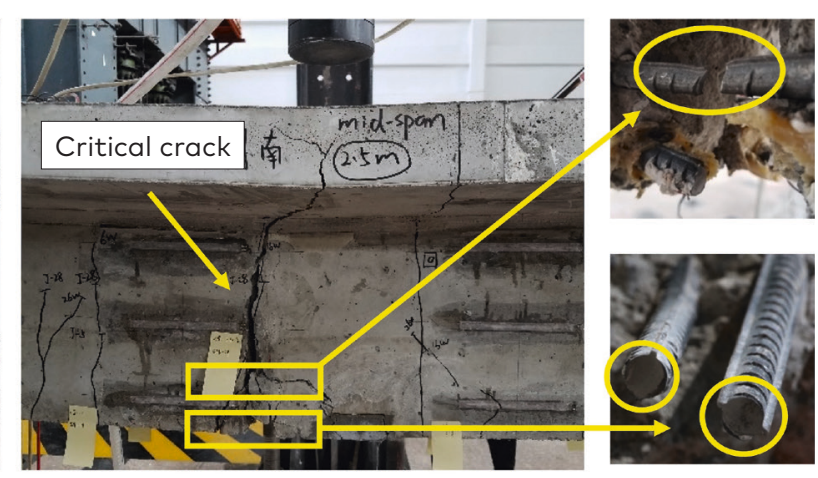

b)

Figure 4. Typical failure modes of RC T-beams under a) static and b) fatigue testing

of the outmost reinforcing bars were found plain and smooth without necking (see Figure 4b), which was significantly different from those caused by yielding. However, the upper layer reinforcing bars showed ductile fracture with necking, as shown in Figure 4b. The following sections summarize the main findings of fatigue tests.

\subsection{Crack evolutions}

The overall cracking pattern relied on the applied load ranges. The cracks initiated from the bottom of the beam and propagated gradually upward. The crack width kept changing during the fatigue testing. After a designated loading cycle and the fatigue load was released, the majority of cracks closed and only a few cracks near the midspan were still visible but with relatively small crack widths $(<0.05 \mathrm{~mm})$, even approaching fatigue failure. The most significant crack near the midspan was used to demonstrate the crack width evolution with cyclic loadings. In order to illustrate the huge crack width difference between pre- and post- failure states, $2 \mathrm{~mm}$ was set consistently for the maximum crack width of failed beams.

The initial crack widths after the first cycle at each upper fatigue load were between $0.02 \mathrm{~mm}$ and $0.14 \mathrm{~mm}$. During the fatigue testing, the crack evolution (total number, width and depth) experienced three stages: rapid developing stage - stable region - final fracture. As shown in Figure 5, beams F-1 to F-5 showed a similar trend in crack width development with the increase of the normalized number of cycles to failure (number of cycles applied / total number of cycles to failure). The first rapid developing stage occurred before $5 \%$ of the fatigue life, 


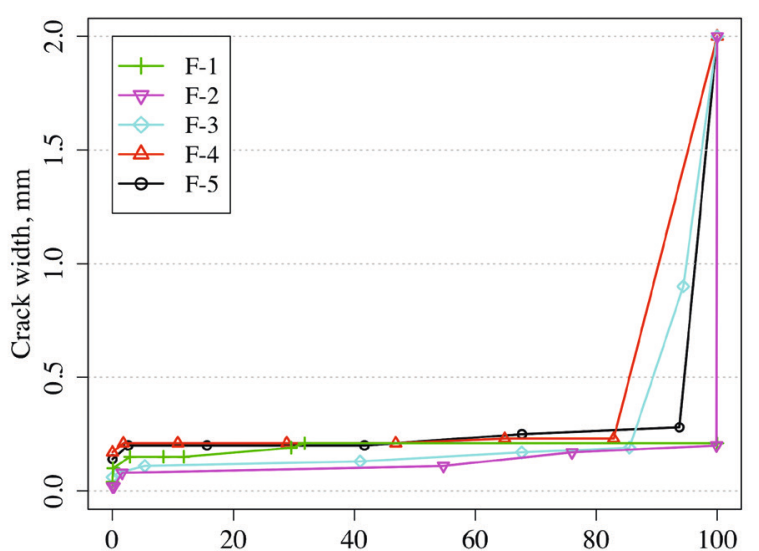

Normalized Number of Cycles to Failure, \%

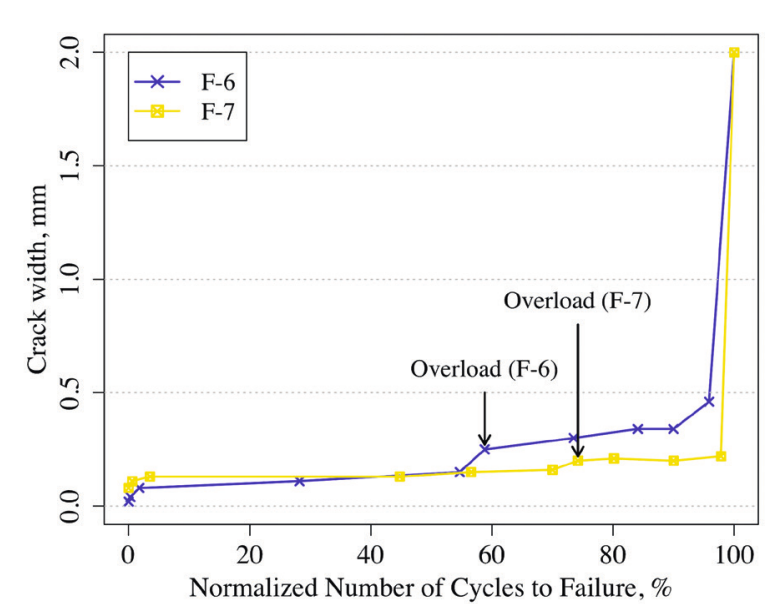

Normalized Number of Cycles to Failure, \%
Fatigue Flexura Performance of Short-Span Reinforced Concrete T-Beams Considering Overloading Effect

b)

Figure 5. Crack widths versus normalized number of cycles to failure for beams a) F-1 to F-5 and b) F-6 \& F-7

in which almost all cracks initiated. Then a long stable region followed and lasted about $80 \%$ to $90 \%$ of the fatigue life. Later on, another rapid increase occurred at the last stage until the beams failed $(80 \%$ to $100 \%$ of the fatigue life). It was observed that only a few cracks near the midspan developed significantly when the beams approached the final fracture, while the other non-critical cracks began to close.

Compared with beams F-1 to F-5 in group (Figure 5a) that had a continuously stable region, a remarkable second increase appeared on beam F-6 (blue solid line in Figure 5b) right after the instant overloading $(7 \mathrm{kN})$ introduction. Such crack width increase was not obvious on beam F-7 owing to a lower overloading level (3.5 kN). 


\subsection{Concrete strain variations in compression}

Concrete strains on the top of sections B-B and C-C were utilized to analyse the concrete strain variations during the fatigue testing. The strain evolutions of beams F-1 to F- 5 behaved in a similar manner and thus only the result of beam F-3 is shown in Figure 6a. The top and bottom curves correspond to the initial (1 cycle) and last (1 060000 cycle) recorded states, respectively. The curves between these two lines represented the stable region. Fatigue failure of concrete in compression was not expected to take place in this experiment in accordance with CEB-FIP Model Code (Federation Internationale du Beton, 2010), since

a)
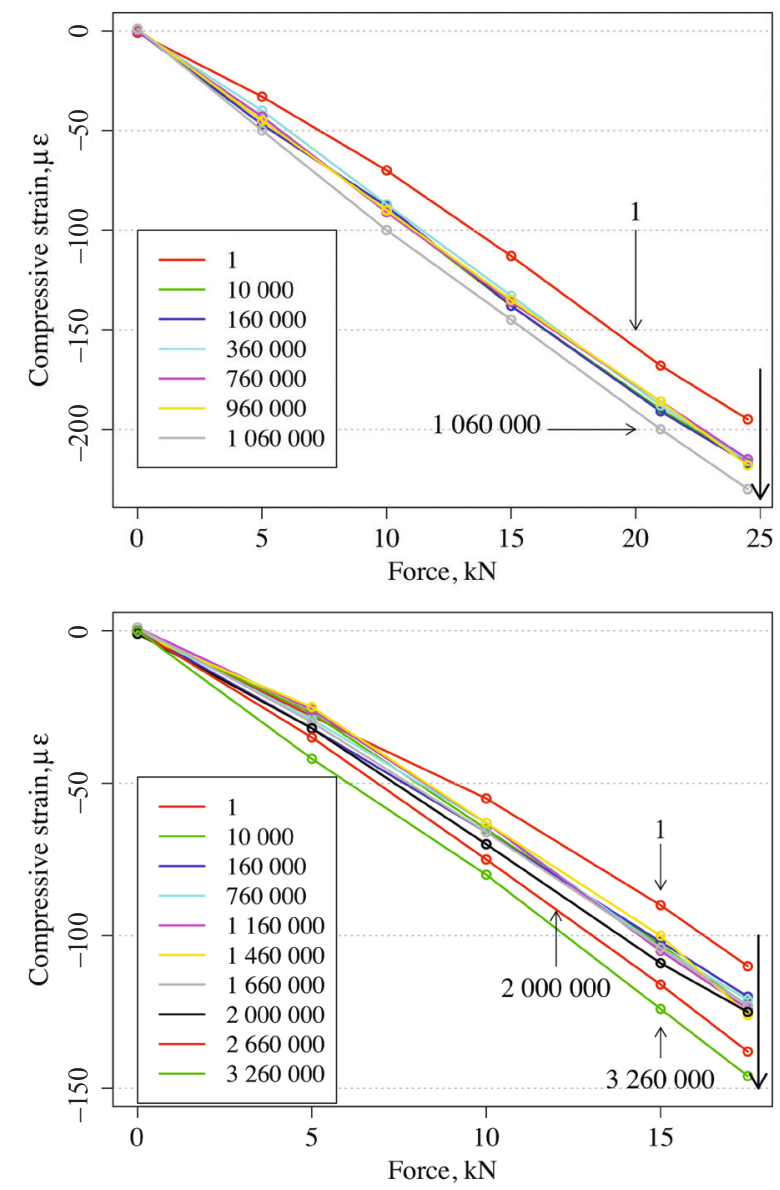

b)

Figure 6. Strain variation in compression zone for beams a) F-3 and b) F-6 
the measured maximum compression strain was relatively small Fatigue Flexural Performance of Short-Span ( $<250 \mu \varepsilon$ for beam F-3) compared to the specified maximum compressive strain $(2000 \mu \varepsilon)$. In contrast, a sudden increase was measured on beams F-6 and F-7, as shown in Figure $6 \mathrm{~b}$ for beam F-6. Owing to the Reinforced

Concrete T-Beams introduction of a $7 \mathrm{kN}$ overloading, the curve at 2 million cycles offsets from the stable region and moved downward to the bottom curve (3 260000 cycles). It served as an indication that the overloading caused a sudden drop of the beam stiffness.

\subsection{Midspan deflection variations}

Figure 7 shows the midspan deflection at the upper fatigue load under quasi-static testing versus normalized number of cycles to failure for all seven beams. For beams F-1 to F-5, deflections increased in the first $5 \%$ fatigue lives, then stayed unchanged or showed a minor increase in the stable region (5\% to $80 \%$ fatigue lives). This observation implied that the beam stiffness maintained almost constant during the fatigue testing. Sudden increases were only observed on beams F-2 and F-3 at the last moment prior to final failure. Although introduced with instant overloading after 2 million cycles, beams F-6 and F-7 behaved in a similar manner with beams F-1 to F-5. Anticipated midspan deflection increases were not observed during the fatigue testing. It was concluded that the midspan deflection variation was not sensitive to the applied instant overloading.

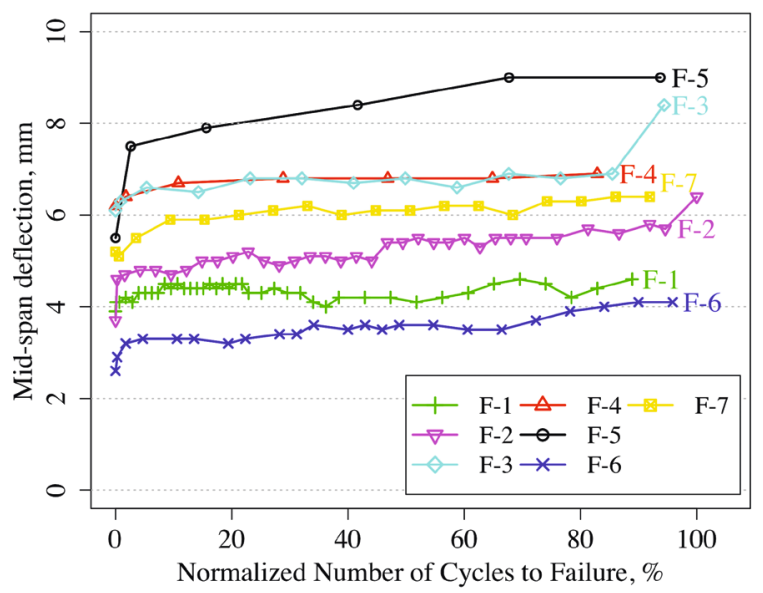

Figure 7. Midspan deflections versus normalized number of cycles 


\subsection{Stress range variations}

The stress range variations in the two outmost tensile reinforcing bars were recorded under each upper fatigue load and the larger values at the midspan were selected for analysis due to the higher fatigue relevance. As shown in Figure 8, beams F-1 to F-5 exhibited a relatively stable region or increased slightly (less than $10 \mathrm{MPa}$ ), thus, the stress ranges (126 $\mathrm{MPa}$ to $300 \mathrm{MPa}$ ) during this period were averaged for fatigue life analysis. Except for unfractured beam F-1, the measured stress ranges (from 195.4 MPa to $428.4 \mathrm{MPa}$ ) at the last moment right

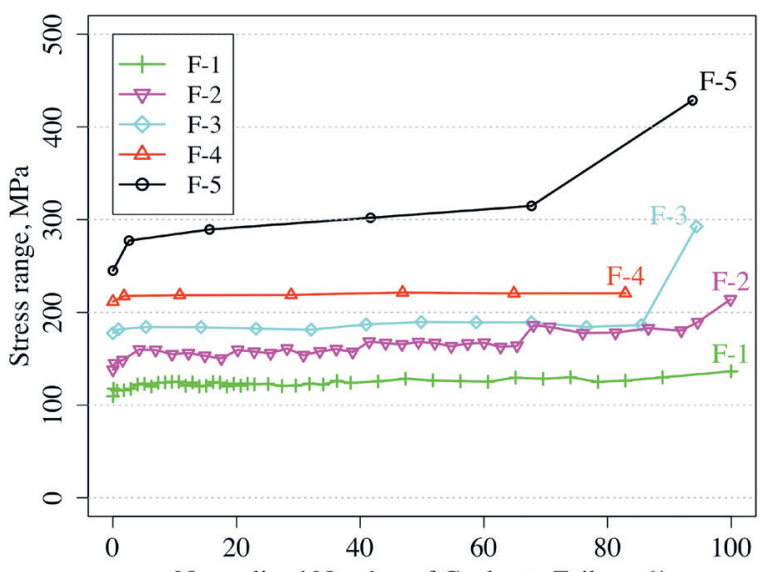

a)

Normalized Number of Cycles to Failure, \%

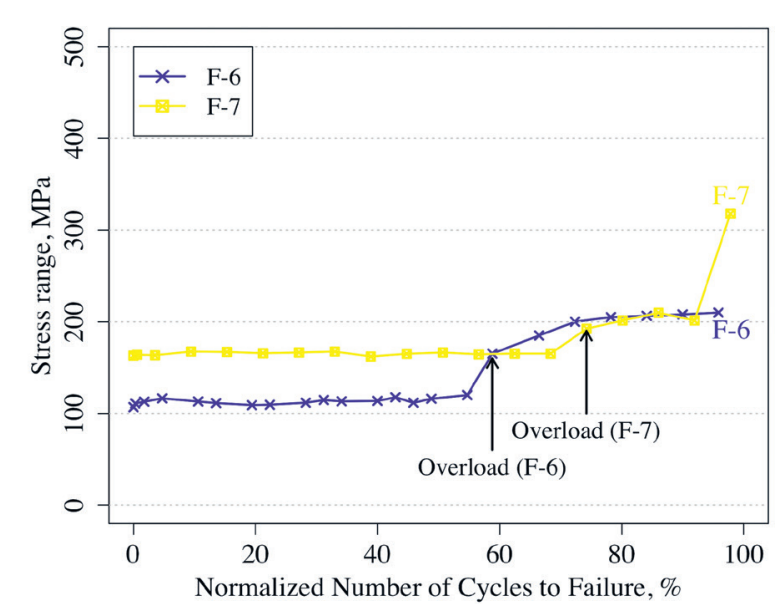

b)

Figure 8. Stress range variations in the outmost tensile reinforcing bars for beams a) F-1 to F-5 and b) F-6 \& F-7 
prior to final failure of beams F-2 to F-5, all exceeded the allowable fatigue limits of $155 \mathrm{MPa}$ prescribed in the AASHTO LRFD Bridge Design Specifications (2012) and $163 \mathrm{MPa}$ in the GB 50010-2015 (2015). In contrast, remarkable stress range increases were observed on beams F- 6 and F-7 after the introduction of $7 \mathrm{kN}$ and $3.5 \mathrm{kN}$ instant overloading from 2 million cycles. After a certain amount of cycles, another stable region was achieved but only maintained for a short period of time. The average stress ranges of beams F-6 and F-7 increased by 53\% (from $121 \mathrm{MPa}$ to $185 \mathrm{MPa}$ ) and 22\% (from $165 \mathrm{MPa}$ to $201 \mathrm{MPa}$ ) after the overloading, respectively.

\section{Effect of instant overloading on the fatigue performance of RC beams}

To investigate the effect of instant overloading, two levels of instant overloading were introduced on beams F-6 and F-7. Beam F-6 was initially subjected to a standard design live load range $(5 \mathrm{kN}$ to $17.5 \mathrm{kN}$ ) for 2 million cycles, corresponding to the expected life for a bridge based on AASHTO LRFD Bridge Design Specifications (2012). After that, a $40 \%$ instant overloading ( $7 \mathrm{kN}$ ) was applied and then the original load range ( $5 \mathrm{kN}$ to $17.5 \mathrm{kN}$ ) was resumed for the fatigue testing. A noticeable average stress range increase in reinforcing bar under the same upper fatigue load $(17.5 \mathrm{kN})$ was captured, which increased from $121 \mathrm{MPa}$ to $185 \mathrm{MPa}$. At the same time, the most critical crack width near the midspan increased from $0.15 \mathrm{~mm}$ to $0.25 \mathrm{~mm}$. Although the instant overloading only lasted for one cycle, an obvious beam stiffness degradation was captured. Compared to beam F-1, F-6 had a similar stress range (126 MPa vs. $121 \mathrm{MPa}$ ) before overloading. Beam F-1 lasted 9 million cycles without failure; however, beam F- 6 only sustained about 1.4 million cycles after the introduction of instant overloading.

A smaller overloading ( $3.5 \mathrm{kN}$ ) was applied on beam F-7, whose initial stress range $(165 \mathrm{MPa})$ was close to the fatigue limit. The design load range ( $5 \mathrm{kN}$ to $21 \mathrm{kN}$ ) was maintained for 2 million cycles as well and then an $20 \%$ instant overloading $(3.5 \mathrm{kN})$ was exerted for one cycle, then the original load range ( $5 \mathrm{kN}$ to $21 \mathrm{kN}$ ) was resumed until its final failure. The average stress range increased from $165 \mathrm{MPa}$ to $201 \mathrm{MPa}$ as a result of overloading. The largest crack width showed an increase from $0.16 \mathrm{~mm}$ to $0.22 \mathrm{~mm}$. Beams F-2 and F-7 were subjected to the same load range in the first 2 million cycles and the average stress ranges were almost the same (163 MPa vs. $165 \mathrm{MPa}$ ). As a result of overloading, the fatigue life of beam F-7 reduced to 2.7 million cycles, which was
Fatigue Flexural

Performance

of Short-Span

Reinforced

Concrete T-Beams

Considering

Overloading Effect 
1.1 million cycles less than the fatigue life of beam F-2 (nearly 3.8 million cycles).

It has been concluded that instant overloading leads to a significant reduction of the fatigue lives of reinforced concrete beams due to the remarkable stress range increases in reinforcing bars.

\section{Fatigue life analysis}

To assess the possibility of fatigue failure, the measured stress range of reinforcing bars is first compared to the allowable fatigue limit. Based on the stress ratio and reinforcing bar type (HRB400) in this research, the fatigue limit calculated from the GB 50010-2015 (2015) ranges from $155 \mathrm{MPa}$ to $163 \mathrm{MPa}$. Similarly, a much more conservative result is also achieved by the AASHTO LRFD Bridge Design Specifications (2012) via Eq. (1). The fatigue limit is obtained as $155 \mathrm{MPa}$ by inputting the minimum stress of $31 \mathrm{MPa}$. It is indicated that only two stress ranges (126 MPa on beam F-1 and $121 \mathrm{MPa}$ on beam F-6) are lower than the allowable fatigue limits. The infinite fatigue life of beam F-1 implies that no fatigue fracture occurs when the stress range is below the fatigue limit. However, beam F-6 failed at 3.4 million cycles as a result of an instant overloading. Except for beam F-1, the remaining six beams failed with average stress ranges between $163 \mathrm{MPa}$ and $300 \mathrm{MPa}$, corresponding to fatigue lives from 3764000 to 384000 cycles in a descending order.

Table 3. S- $N$ curves in the current codes and specifications

\begin{tabular}{|c|c|c|}
\hline Categories & Code/Specification & Equation \\
\hline \multirow{4}{*}{ Steel } & GB 50017-2017 (2017) & $\log N=15.13-4.38 \log \Delta \sigma$ \\
\hline & $\begin{array}{l}\text { LFRD for Highway Bridge } \\
\text { Superstructure (2007) }\end{array}$ & $\log N=12.91-3 \log \Delta \sigma$ \\
\hline & \multirow{2}{*}{ Eurocode 3} & $\log N=12.91-3 \log \Delta \sigma\left(N<5 \cdot 10^{6}\right)$ \\
\hline & & $\log N=17.05-5 \log \Delta \sigma\left(N>5 \cdot 10^{6}\right)$ \\
\hline \multirow{4}{*}{$\begin{array}{l}\text { Reinforcing } \\
\text { bar }\end{array}$} & \multirow{2}{*}{$\begin{array}{l}\text { CEB-FIP Model Code (2010), } \\
d<16 \mathrm{~mm}\end{array}$} & $\log N=17.61-5 \log \Delta \sigma\left(N<10^{6}\right)$ \\
\hline & & $\log N=26.87-9 \log \Delta \sigma\left(N>10^{6}\right)$ \\
\hline & \multirow{2}{*}{$\begin{array}{l}\text { CEB-FIP Model Code (2010), } \\
d>16 \mathrm{~mm} \text { or Eurocode } 2\end{array}$} & $\log N=17.02-5 \log \Delta \sigma\left(N<10^{6}\right)$ \\
\hline & & $\log N=25.80-9 \log \Delta \sigma\left(N>10^{6}\right)$ \\
\hline
\end{tabular}


Furthermore, beams F-1 to F-5 were selected to establish an $S-N$ curve. Beams F-6 and F-7 were not taken into consideration due to the instant overloading. Five points (asterisk symbol) with a single-log scale are plotted in Figure 9. The best-fit line ( $S-N$ curve) equation is obtained as

$$
\log N=14.93-3.84 \log \Delta \sigma \text {, }
$$

where $N$ is the number of cycles to failure and $\Delta \sigma$ is the average stress range in the outmost tensile reinforcing bars.

The first edition of reinforcing bar $S-N$ curve was proposed in Eurocode 2 (British Standards Institution, 2004), in which the fatigue strength (corresponding to the fatigue life at 1 million cycles) equals to $162.5 \mathrm{MPa}$. Later on, a modification was achieved in the CEB-FIP Model Code (2010) based on the finding that the bar diameter increases leaded to a reduction of fatigue strength, as concluded by and Helagson and Hanson (1974) and Walker, Austen, Harrison, and Morley (1975). Therefore, the modified $S-N$ curves are divided into two groups separated by a bar diameter of $16 \mathrm{~mm}$. The group with a bar diameter larger than $16 \mathrm{~mm}$ kept the same expression with Eurocode 2, whereas the fatigue limit showed a 30\% increase for bar diameters less than 16

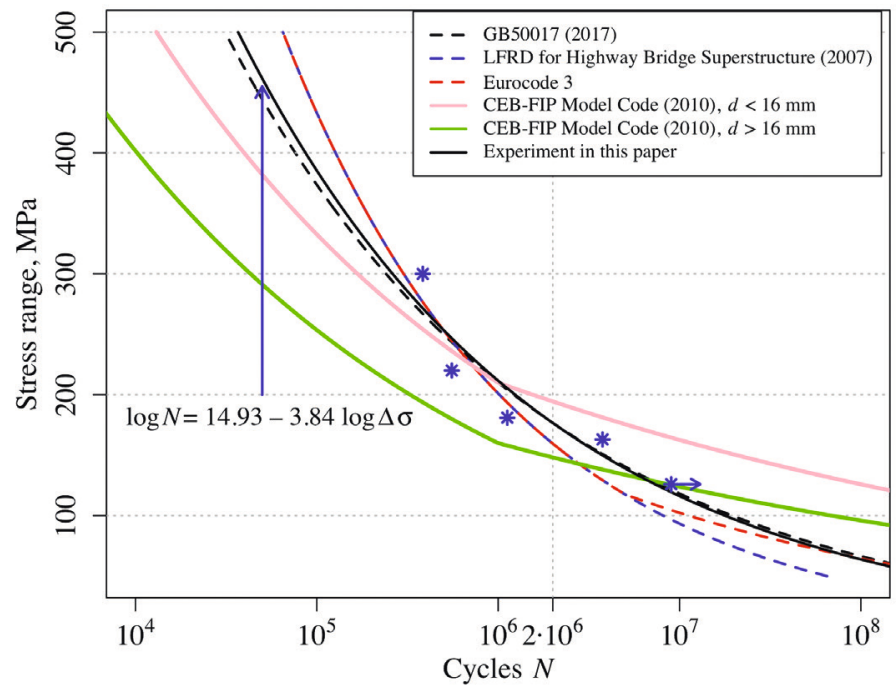

Figure 9. Experimental results and official steel and reinforcing bar S-N curves (the star symbol with a right arrow means an infinite life)
Fatigue Flexural Performance of Short-Span Reinforced Concrete T-Beams Considering Overloading Effect 
$\mathrm{mm}$. Two solid lines in Figure 9 represent the $S$ - $N$ curves for reinforcing bars in the CEB-FIP Model Code (2010). It is concluded that the $S$ - $N$ curve with bar diameter larger than $16 \mathrm{~mm}$ gives a relatively conservative prediction. However, the $S$ - $N$ curve with bar diameters less than $16 \mathrm{~mm}$ shows an overestimation for beams with large stress ranges.

Alternatively, steel $S$ - $N$ curves [Eurocode 3 (British Standards Institution, 2005), LRFD for Highway Bridge Superstructure (Federal Highway Administration, 2007) and GB 50017-2017 (Ministry of Housing and Urban-Rural Development of PRC, 2017)] are still used in a rational manner to predict fatigue life of reinforced concrete structures. For example, based on the steel $S$ - $N$ curve in Eurocode 3 as well as the Miner's rule, the fatigue life of reinforced concrete beams was evaluated by Wang and Zhai (2013) and Wang, Zhai, Duan, and Wang (2015). As shown in Figure 9, these three steel $S$ - $N$ curves with base metal category (dash lines) indicate a similar fatigue behaviour of steels manufactured in China, United States and Europe. It can be observed that the five experimental results lie close to the dash lines, as compared with the solid lines. It implies that the steel $S$ - $N$ curve might be a good alternative to estimate fatigue lives, but the reinforcing bar $S$ - $N$ curve with bar diameter larger than $16 \mathrm{~mm}$ is much more suitable for bridge design purpose, which incorporates a large safety margin for real service conditions.

\section{Conclusions}

The fatigue performance of short-span reinforced concrete T-beams was comprehensively investigated in this paper. The conclusions are as follows.

1. With regard to conventional short-span RC beams, failure mode under static testing is the crushing of concrete in compression prior to the ductile fracture of tensile reinforcing bars. In contrast, fatigue fracture of the outmost tensile reinforcing bars is the failure mode under fatigue testing.

2. Under the design live load and $20 \%$ above, Beams F-1 and F-2 achieved at least 2 million loading cycles, in excess of the anticipated fatigue life for a bridge. The stress ranges of reinforcing bars in these two beams were both within the fatigue limits specified in GB 50010-2015 (2015) and AASHTO LRFD Bridge Design Specifications (2012), which provided fatigue examination for design purposes.

3. When subjected to higher load ranges $(40 \%, 60 \%$, and $100 \%$ above the design load), beams F-3 to F-5 failed to sustain 2 million loading cycles and showed a pronounced decrease of fatigue lives. 
4. With one cycle of a $40 \%$ overloading right after 2 million cycles, Beam F-6 only sustained another 1.4 million loading cycles, compared to an expected unlimited fatigue life under pre-set fatigue load range. Similarly, with the introduction of one cycle of $20 \%$ instant overloading, an abrupt fatigue failure took place on beam F-7 after only another 0.7 million cycles. It was concluded that overloading would result in a tremendous reduction of fatigue life due to the pronounced stress range increase.

5. The fatigue life is most sensitive to the stress range variation of the reinforcing bars compared to effect of deflections, concrete strains, and crack evolutions.

\section{Acknowledgements}

The authors gratefully acknowledge the financial support provided by The Special Fund of Chinese Central Government for Basic Scientific Research Operations in Commonweal Research Institutes under Grant [2017-9035].

\section{REFERENCES}

Al-Qadi, I. L., Wang, H., Ouyang, Y., Grimmelsman, K., \& Purdy, J. E. (2016). LTBP program's literature review on weigh-in-motion systems. United States. Federal Highway Administration. Office of Infrastructure Research and Development.

American Association of State Highway and Transportation Officials. (2012). AASHTO LRFD bridge design specifications.

American Concrete Institute. (1997). ACI 215R-74: Considerations for design of concrete structures subjected to fatigue loading.

Biezma, M. V., \& Schanack, F. (2007). Collapse of steel bridges. Journal of Performance of Constructed Facilities, 21(5), 398-405. https://doi.org/10.1061/(ASCE)0887-3828(2007)21:5(398)

Bishara, A. G. (1982). Some aspects of dynamic response of rectangular reinforced concrete beams. Special Publication, 75, 235-252.

British Standards Institution. (2004). Eurocode 2: Design of concrete structures: Part 1-1: General rules and rules for buildings.

British Standards Institution. (2005). Eurocode 3: Design of steel structures. Part 1-9: Fatigue.

Corley, W. G., Hanson, J. M., and Helgason, T. (1978). Design of reinforced concrete for fatigue. Journal of Structure Division, ASCE, 104(6), 921-932.

Federal Highway Administration. (2007). Load and Resistance Factor Design (LRFD) for Highway Bridge Superstructures. 
Federation Internationale du Beton. (2010). Model Code 2010.

Gatti, M. (2019). Structural health monitoring of an operational bridge: A case study. Engineering Structures, 195, 200-209.

https://doi.org/10.1016/j.engstruct.2019.05.102

Standardization Administration of the People's Republic of China. (2015). GB 50010-2015: Code for design of concrete structures.

Han, W., Wu, J., Cai, C., \& Chen, S. (2014). Characteristics and dynamic impact of overloaded extra heavy trucks on typical highway bridges. Journal of Bridge Engineering, 20(2), 05014011. https://doi.org/10.1061/(ASCE)BE.1943-5592.0000666

Heffernan, P., \& Erki, M. (2004). Fatigue behavior of reinforced concrete beams strengthened with carbon fiber reinforced plastic laminates. Journal of Composites for Construction, 8(2), 132-140. https://doi.org/10.1061/(ASCE)1090-0268(2004)8:2(132)

Helagson, T., \& Hanson, J. (1974). Investigation of design factors affecting fatigue strength of reinforcing bars-statistical analysis. Special Publication, 41, 107-138.

Helgason, T., Hanson, J. M., Somes, N. F., Corley, W., \& Hognestad, E. J. N. R. (1976). Fatigue strength of high-yield reinforcing bars. ACI Journal, 71(164).

Herwig, A. (2008). Reinforced concrete bridges under increased railway traffic loads. PhD Dissertation, Swiss Federal Institute of Technology, Lausanne, Switzerland.

Highway Research Board. (1962). The AASHO road test. Report 7. Summary Report.

Johansson, U. (2004). Fatigue tests and analysis of reinforced concrete bridge deck models. MSc Thesis, Royal Institute of Technology, Stockholm, Sweden.

Maddah, N. (2013). Fatigue life assessment of roadway bridges based on actual traffic loads. PhD Dissertation, Swiss Federal Institute of Technology, Lausanne, Switzerland.

Mallet, G. P. (1991). Fatigue of reinforced concrete. London: HMSO Publications Centre.

Matsumoto, N., Yumazumi, K., \& Miyamoto, Y. (1990). A study of fatigue life of reinforced concrete beam with multiple tension reinforcing bars. Railway Technical Research Institute, Quarterly Reports, 31(3).

Menzies, J. B. (1971). The fatigue strength of steel reinforcement in concrete. Building Research Station, U.K., Current Paper CP 16/71.

Ministry of Housing and Urban-Rural Development of PRC. (2017). GB 50017-2017: Standard for design of steel structures.

Mirzazadeh, M. M., Noël, M., \& Green, M. F. (2017). Fatigue behavior of reinforced concrete beams with temperature differentials at room and low temperature. Journal of Structural Engineering, 143(7), 04017056. https://doi.org/10.1061/9780784480427.025

Nagesh, H. E., \& Rao, G. A. (2016). Fatigue behavior of lightly reinforced concrete beams in flexure due to overload. In 9th International conference on fracture mechanics of concrete and concrete structures. California, USA, 22-25 May 2016. 
National Standard of the People's Republic of China. (2017). GB/T 1499.1-2017: Steel for the reinforcement of concrete - Part 1: Hot rolled plain bars.

National Standard of the People's Republic of China. (2018). GB/T 1499.2-2018: Steel for the reinforcement of concrete - Part 2: Hot rolled ribbed bars.

Olsson, K., \& Pettersson, J. (2010). Fatigue assessment methods for reinforced Performance of Short-Span Reinforced Concrete T-Beams Considering concrete bridges in eurocode. comparative study of design methods for railway bridges. MSc Thesis, Chalmers University of Technology, Sweden.

Papakonstantinou, C. G., Petrou, M. F., \& Harries, K. A. (2001). Fatigue behavior of RC beams strengthened with GFRP sheets. Journal of Composites for Construction, 5(4), 246-253. https://doi.org/10.1061/(ASCE)1090-0268(2001)5:4(246)

Pimentel, M., Brühwiler, E., \& Figueiras, J. (2008). Fatigue life of short-span reinforced concrete railway bridges. Structural Concrete, 9(4), 215-222. https://doi.org/10.1680/stco.2008.9.4.215

Roper, H., \& Hetherington, G. (1982). Fatigue of reinforced concrete beams in air, chloride solution, and sea water. Special Publication, 75, 307-330.

Schlalli, M., \& Briihwiler, E. (1998). Shear fatigue failure of reinforced concrete elements without shear reinforcement. In Proceedings of the 12th Biennial Conference on Fracture (ECF-12), U.K., Sheffield, 14-18 September 1998.

Soltani, A., Harries, K. A., Shahrooz, B. M., Russell, H. G., \& Miller, R. A. (2011). Fatigue performance of high-strength reinforcing steel. Journal of Bridge Engineering, 17(3), 454-461. https://doi.org/10.1061/(ASCE)BE.1943-5592.0000281

Tarifa, M., Zhang, X., Ruiz, G., \& Poveda, E. (2015). Full-scale fatigue tests of precast reinforced concrete slabs for railway tracks. Engineering Structures, 100, 610-621. https://doi.org/10.1016/j.engstruct.2015.06.016

Teworte, F., Herbrand, M., \& Hegger, J. (2015). Structural assessment of concrete bridges in germany-Shear resistance under static and fatigue loading. Structural Engineering International, 25(3), 266-274.

https://doi.org/10.2749/101686615X14210663188411

The Standardization Administration of the People's Republic of China. (2015). JTG D60-2015: General specifications for design of highway bridges and culverts.

Transport Planning and Research Institute (Ministry of Transport China). (1984). JT/GQS 025-1984: Road bridge and culvert design drawing prefabricated reinforced concrete T-beams.

Treacy, M. A., \& Brühwiler, E. (2013). Extreme action effects in reinforced concrete bridges from monitoring. IABSE Symposium Report, 99(27), 341-348. https://doi.org/10.2749/222137813806474642

Walker, E., Austen, I., Harrison, T., \& Morley, J. (1975). Fatigue and corrosion fatigue of reinforcement bars. In Proc. Conf. Underwater Construction Technology. Department of Civil and Structural Engineering Report, University College, Cardiff.

Wang, C., \& Zhai, M. (2013). Fatigue safety monitoring and fatigue life evaluation for existing concrete bridges. In 13th International Conference on Fracture. Beijing, China, 16-21 June 2008. 
Wang, C., Zhai, M., Duan, L., \& Wang, Q. (2015). Fatigue service life evaluation of existing steel and concrete bridges. Advanced Steel Construction, 11(3), 305-321. https://doi.org/10.18057/IJASC.2015.11.3.5

Wardhana, K., \& Hadipriono, F. C. (2003). Analysis of recent bridge failures in the United States. Journal of performance of constructed facilities, 17(3), 144-150. https://doi.org/10.1061/(ASCE)0887-3828(2003)17:3(144)

Yuan, M., Yan, D., Zhong, H., \& Liu, Y. (2017). Experimental investigation of high-cycle fatigue behavior for prestressed concrete box-girders. Construction Building Materials, 157, 424-437. https://doi.org/10.1016/j.conbuildmat.2017.09.131

Zhang, J., Li, P., Mao, Y., \& Dong, Z. (2019). The mechanical properties of reinforced concrete plate-girders when placed under repeated simulated vehicle loads. Materials, 12(11), 1831. https://doi.org/10.3390/ma12111831

Zhang, J., Peng, H., \& Cai, C. (2010). Field study of overload behavior of an existing reinforced concrete bridge under simulated vehicle loads. Journal of Bridge Engineering, 16(2), 226-237.

https://doi.org/10.1061/(ASCE)BE.1943-5592.0000140 